\title{
Cardiac hypertrophy and thyroid hormone signaling
}

\author{
Wolfgang Dillmann
}

Published online: 6 January 2009

(c) The Author(s) 2008. This article is published with open access at Springerlink.com

\begin{abstract}
Thyroid hormone exerts a large number of influences on the cardiovascular system. Increased thyroid hormone action increases the force and speed of systolic contraction and the speed of diastolic relaxation and these are largely beneficial effects. Furthermore, thyroid hormone has marked electrophysiological effects increasing heart rate and the propensity for atrial fibrillation and these effects are largely mal-adaptive. In addition, thyroid hormone markedly increases cardiac angiogenesis and decreases vascular tone. These multiple thyroid hormone effects are largely mediated by the action of nuclear based thyroid hormone receptors (TR) the thyroid hormone receptor alpha and beta. TR $\alpha$ is the predominant isoform in the heart. Rapid nongenomic thyroid hormone effects also occur, which can be clearly demonstrated in ex-vivo experiments. Some of the most marked thyroid hormone effects in cardiac myocytes involve influences on calcium flux, with thyroid hormone promoting expression of the gene encoding the calcium pump of the sarcoplasmic reticulum (SERCa2). In contrast, in hypothyroid animals phospholamban levels, which inhibit the SERCa2 pump, are increased. In addition, marked effects are exerted on the calcium channel of the sarcoplasmic reticulum the ryanodine channel. Related to myofibrillar proteins, myosin heavy chain alpha is increased by $\mathrm{T} 3$ and MHC beta is decreased. Complex and interesting interactions occur between cardiac hypertrophy induced by excess thyroid hormone action and cardiac hypertrophy occurring with heart failure. The thyroid hormone mediated cardiac hypertrophy in its initial phases presents a physiological hypertrophy with increases in SERCa2 levels and
\end{abstract}

W. Dillmann $(\square)$

University of California, San Diego, USA

e-mail: wdoffice@ucsd.edu decreased expression of MHC beta. In contrast, pressure overload induced heart failure leads to a "pathological" cardiac hypertrophy which is largely mediated by activation of the calcineurin system and the MAPkinases signaling system. Recent evidence indicates that heart failure can lead to a downregulation of the thyroid hormone signaling system in the heart. In the failing heart, decreases of thyroid hormone receptor levels occur. In addition, serum levels of T4 and T3 are decreased with heart failure in the frame of the non-thyroidal illness syndrome. The decrease in $\mathrm{T} 3$ serves as an indicator for a bad prognosis in the heart failure patient being linked to increased mortality. In animal models, it can be shown that in pressure overload-induced cardiac hypertrophy a decrease of thyroid hormone receptor levels occurs. Cardiac function can be improved by increasing expression of thyroid hormone receptors mediated by adeno-associated virus based gene transfer. The failing heart may develop a "hypothyroid" status contributing to diminished cardiac contractile function.

Keywords Thyroid hormone action - Thyroid hormone receptors · Heart failure - Non-thyroidal illness syndrome Hypothyroidism $\cdot$ Calcium flux

\section{Introduction}

Thyroid hormone exerts a large number of influences on the cardiovascular system involving cardiac contractile effects, electrophysiological function, and cardiac structure [1-3]. In addition, vascular tone, lipid levels and oxygen consumption are markedly influenced by the thyroid status. Related to cardiac contraction, thyroid hormone stimulates the rate and force of systolic contraction and the rate of 
diastolic relaxation [3]. These beneficial cardiovascular effects occur in animal models and patients with heart failure. Electrophysiological effects manifest themselves as an increased heart rate, which is sometimes apparent as resting tachycardia in patients with hyperthyroidism. In addition, an increased propensity to arrhythmias especially atrial arrhythmias and atrial fibrillation occurs [4, 5]. Increased thyroid hormone action of some duration markedly stimulates the cardiac protein synthesis and leads to a concentric cardiac hypertrophy [6,7]. Return from a hyperthyroid to a eu-thyroid status results in a return of the cardiac hypertrophy to a normal cardiac configuration. In addition, less well recognized effects of thyroid hormones are exerted on the cardiac vascular system with a promotion of angiogenesis [8, 9]. Increased thyroid hormone action leads to a decrease of the tone of arterial vascular smooth muscle and a markedly decreased cardiac afterload [10]. In contrast $20-40 \%$ of patients with hypothyroidism can exhibit an increase in blood pressure [11]. Thyroid hormone action also effects lipid level. Hypothyroidism leads to increased cholesterol levels because of decreased clearance and increased levels of LDL [12, 13]. Overall, thyroid hormone stimulates metabolic rate and oxygen consumption which results in a loss of body weight in the majority of patients with hyperthyroidism.

\section{Mechanisms of thyroid hormone action in the cardiovascular system}

Thyroid hormone acts in large part by binding to nuclear thyroid hormone receptors [14]. Binding of the T3 ligand to the thyroid hormone receptor results for a great majority of genes in their increased transcription. In the absence of the ligand $\mathrm{T} 3$, the thyroid hormone receptor can repress the expression of genes leading to gene silencing. The communication between the thyroid hormone and the basal transcription machinery occurs through a complex set of co-activators and co-repressors [15]. The ligand-activated thyroid hormone receptor recruits co-activators which have a positive stimulatory interaction with the basic transcriptional machinery. In contrast recruitment of thyroid hormone related co-repressors leads to decreased transcription of thyroid hormone responsive genes. Thyroid hormone responsive genes contain thyroid hormone response elements (TRE's) in their promoter, which can be configured as cononical elements consisting of two direct six nucleotide repeats spaced by a four nucleotide sequence [14]. Other elements are composed as palindromic or inverted palindromic TRE's, and in addition, highly complex TRE's have been described [16]. Two genes, thyroid hormone receptor alpha and thyroid hormone receptor beta, encode thyroid hormone receptors. The thyroid hormone receptor alpha gene encodes the ligand-activated thyroid hormone receptor alpha 1 receptor. Due to alternate splicing, thyroid hormone receptor alpha 2 does not bind to thyroid hormone and has a weak silencing effect $[14,16]$. In addition, short delta fragments of the thyroid hormone receptor are expressed, which do no include the $\mathrm{N}$ and $\mathrm{C}$ terminal portions of the T3 receptor protein [17]. This TR delta alpha 1 and TR delta 2 fragments exert a dominant negative effect. A specific splice variant of the thyroid hormone receptor alpha, which is preferentially expressed in mitochondria (P43, P28) has been described [18]. For the thyroid receptor beta, the major transcript which is ubiquitously present is the $\mathrm{T} 3$ binding thyroid hormone receptor beta 1 isoform. The TR beta 2 isoform has a different $\mathrm{N}$-terminal configuration and is preferentially expressed in the central nervous system and the pituitary. In addition, a TR beta 3 isoform is expressed in an ubiquitous fashion at low levels and a delta isoform TR delta beta 3 is expressed which exerts dominant negative effects [16]. The mediation of nuclear T3 receptor-based thyroid hormone action is therefore a complex process which is influenced by the thyroid hormone concentration and the level and type of the thyroid hormone receptors alpha and beta isoforms. In addition the thyroid hormone receptors can form homo and heterodimers, which is the most frequently occurring form. The configuration of the thyroid hormone response elements onto which the TR binds, also influences the thyroid hormone action. The important role of interactions with co-repressors and co-activators was already indicated and the interactions with cell-type specific factors can occur. These interactions lead to changes in the histone acetylation status of chromatin.

In addition to the classical nuclear thyroid hormone receptor-based mediation of $\mathrm{T} 3$ action recently rapid effects of thyroid hormone especially in cell culture experiments have been demonstrated [19]. The importance of these effects under in vivo conditions is currently explored actively. These rapid effects of thyroid hormone may be mediated by the binding of thyroid hormone to integrin-based receptors on the cell surface. It is also possible that a subplasma membrane compartment of thyroid hormone receptors exist, as it has been described for the estrogen receptor [20].

\section{From gene to contractile effect}

The diastolic function of the heart is influenced by the thyroid status in a marked fashion. Hypothyroidism is frequently combined with delayed diastolic relaxation of the heart. The speed of diastolic relaxation of the heart is markedly influenced by the lowering of the calcium levels. In the mammalian cardiac myocyte, $70-90 \%$ of calcium 
lowering is achieved by pumping of calcium into the sarcoplasmic reticulum by the calcium ATPase of the sarcoplasmic reticulum. This ATP consuming calcium pump is inhibited by phospholamban. The phosphoalation of phospholamban removes this inhibitory effect. In order to demonstrate how thyroid hormone effects can alter the expression of a specific gene leading to a contractile phenotype, the expression of the SERCa2 gene is considered. Experiments in our laboratory using nuclear run-on assays demonstrated that thyroid hormone stimulates the transcription of the SERCa2 gene. We analyzed the promoter of the SERCa2 gene in detail and found three different thyroid hormone response elements. One of the elements is a direct repeat and the second and the third element are inverted palindromic elements. The thyroid hormone response elements were mutated to non-functional TRE's which eliminated thyroid hormone effects on the activation of the SERCa2 promoter [21, 22]. These mutational studies also revealed that the first TRE was the most powerful one in mediating a stimulatory effect on the SERCa2 gene. Thyroid hormone also effects the expression of phospholamban. In the hypothyroid, heart phospholamban levels are increased which will lead to an inhibition of SERCa2. The mRNA level of the ryanodine channel is also markedly increased with an increased thyroid status [2]. In addition to influences on calcium handling, thyroid hormone influences the expression of myofibrillar proteins in important ways. Thyroid hormone exerts a positive effect on the transcription of the myosin heavy chain MHC alpha gene inhibiting MHC $\beta$ [2]. In contrast the mRNA and protein levels of myosin heavy chain beta are decreased in hypothyroid animals. Recent interesting studies have indicated that MHC expression is modulated by micro RNA's which influence MHC mRNA turnover and translation [23].

\section{Predominance of thyroid hormone receptor TR alpha and beta in the heart and influences of thyroid hormone receptor depletion}

To explore in further detail the influence which the thyroid hormone receptor isoforms TR alpha and TR beta have on cardiac function, mice with an ubiquitous constitutional knock out (KO) of TR $\alpha$ and TR $\beta$ were used. The Tr $\alpha$ KO and TR $\beta$ KO mice were generated by J. Samarut (Lyon, France) [24] and provided on a collaborative basis. In TR $\beta$ KO mice, alpha Exon 5, 6, and 7 are deleted [24] and for the thyroid hormone receptor beta Exon 4 and 5 are removed [25]. TR $\alpha$ KO mice have low normal thyroid hormone levels. In contrast, mice with deletion of TR $\beta$ are hyperthyroid most likely due to the loss of the inhibitory effects of TR $\beta$ on TSH expression. In order to achieve a euthyroid status, the TR $\beta$ KO mice are placed on a low
iodine/PTU diet and then replaced with a physiological dose of thyroid hormone. Cardiac papillary function in $\mathrm{TR} \alpha \mathrm{KO}$ and TR $\beta \mathrm{KO}$ knockout mice has been determined $[26,27]$. Cardiac capillary muscle function in TR $\alpha \mathrm{KO}$ mice were markedly abnormal showing delayed time for relaxation and decreased tension development [26]. In contrast, the cardiac papillary muscle from TR $\beta$ KO mice exhibited normal contractile function. In addition, mice with the deletion of $\operatorname{TR} \alpha$ have a lower heart rate whereas $\operatorname{TR} \beta \mathrm{KO}$ mice exhibit a normal heart rate [26, 28]. The contractile abnormalities observed in the hearts of TR $\alpha \mathrm{KO}$ mice are in line with the fact that thyroid hormone receptor alpha at the mRNA and protein level presents $70 \%$ of all thyroid hormone receptor present with thyroid hormone receptor beta 1 accounting for the remaining $20 \%$. The marked effect of thyroid hormone receptor alpha deletion on contractile function could be explained by the fact that thyroid hormone receptor alpha is the more predominant receptor or it also could be due to specific qualitative characteristics of the thyroid hormone receptor alpha which are different from those of thyroid hormone receptor beta. Quantitative versus qualitative effects of TR isoforms are further discussed below.

We also wanted to explore if the decrease in SERCa2 expression makes a significant contribution to the delayed diastolic contraction observed in hypothyroid mice. Transgenic mice in which the SERCa2 transgene is driven by a promoter not containing thyroid hormone response elements were generated [27]. These transgenic mice and wild type mice are made hypothyroid. Hypothyroid wild type mice show delayed diastolic cardiac relaxation or delayed relaxation of papillary muscle. In contrast, SERCa2 transgenic mice made hypothyroid exhibit a normal contractile phenotype related to diastolic relaxation or relaxation of papillary muscle. These findings therefore indicate that the diastolic contractile effects mediated by hypothyroidism are largely influenced by the calcium handling of myocytes and decreased SERCa2 expression. Holding SERCa2 levels in hypothyroid transgenic animals at the normal levels leads to normal diastolic contractile function.

\section{Interaction between thyroid status cardiac hypertrophy and heart failure}

A longstanding debate has occurred in the literature if cardiac hypertrophy can be separated into a physiological versus a pathological type of cardiac hypertrophy $[29,30]$. Physiological hypertrophy can be induced by exercise or by increased thyroid hormone action. It is characterized by increased SERCa2 levels, increased myosin heavy chain (MHC) alpha levels, and decreased MHC beta levels. In 
contrast, pathological hypertrophy is, for example, mediated by increase in pressure overload or hypertension with the heart contracting against an increased after load. Some of its hallmarks are decreases in SERCa2 levels, decreases in $\mathrm{MHC} \alpha$ levels, and increases in MHC $\alpha$ levels.

It has been proposed that different signaling members mediate cardiac hypertrophy in physiological vs. pathological hypertrophy. For physiological hypertrophy, one of the models proposes that IGF1 binds to its receptor on cardiac myocyte. This stimulates the activation of PI3 kinase leading to AKT phosphorylation which then initiates changes in gene expression which are compatible with the physiological cardiac hypertrophy phenotype. In contrast, major players in pathological cardiac hypertrophy include the activation of MAP kinase cascade with ERK1/2, p38 MAPK and JNK 1/2/3 [29]. In addition, the calcineurin system plays an important role in pathological cardiac hypertrophy [31]. A clear separation between physiological and pathological hypertrophy is properly not feasible, and over time, a compensated physiological hypertrophy may result in cardiomyopathic dilatation and pathological type of hypertrophy [30]. Interesting studies in which an AKT transgene was expressed in a conditional manner in cardiac myocytes showed that initially the hearts showed a phenotype which is compatible with physiological hypertrophy. However, after 20 weeks duration, a phenotype, which is more compatible with a dilated cardiomyopathy resulting in decreased fractional shortening, occurred [32]. A contributing factor in the transition to a pathological hypertrophy may have been inadequate vascular supply by capillary density not keeping pace with the enlarging heart.

In summary, hyperthyroidism of limited duration can lead to a compensated concentric cardiac hypertrophy. Since hyperthyroidism is in general of a limited duration, a physiological hypertrophic phenotype prevails. It also needs to be noted that in hyperthyroid patients, tachycardia and atrial fibrillation can occur and some of the heart failure observed in hyperthyroid patients may result from rate related heart failure. Experiments using healthy dogs indicate that pacing their hearts at an increasing rate results in heart failure [33]. It also should be noted that patients with hyperthyroidism who developed congestive heart failure and a dilated cardiomyopathy have been reported [34, 35] but this is an infrequent outcome. It is possible that these patients did have underlying heart disease. It should also be noted that in patients with hyperthyroidism, pulmonary hypertension and right heart failure can occur [36, 37].

\section{Hypothyroidism and heart failure}

Several reports in the literature have indicated that hypothyroidism can result in dilated cardiomyopathy and congestive heart failure [38, 39]. In addition, subclinical hypothyroidism can also increase the risk for heart failure [40]. In one report, a cardiac biopsy was undertaken because a cardiac transplant was planned before the hypothyroidism was diagnosed [41]. The mRNA analysis from the patient's heart, when he was severely hypothyroid indicated that $\mathrm{MHC} \alpha$ was of markedly lower predominance than after treatment for the hypothyroidism had occurred with opposite changes for MHC $\beta$. In addition, ANF mRNA was markedly elevated in the hypothyroid heart and not detectable in the normal heart. Related to proteins involved in calcium handling, phospholamban levels were 10-fold higher in the hypothyroid than in the eu-thyroid heart [41]. Results in various animal models of hypothyroidism indicate that the level and activity of SERCa2 is markedly decreased and similar changes occur in animals or patients with heart failure $[42,43]$. These changes can be linked to a decrease in diastolic relaxation. In addition, phospholamban levels are markedly increased at the mRNA levels in hypothyroid and failing hearts, further contributing to decreased SERCa2 function and delayed diastolic relaxation [44, 45]. The ryanodine receptor is markedly decreased in hypothyroid hearts [46] and due to alterations in ryanodine receptor phosphorylation in failing hearts, problems with appropriate calcium handling occur [47]. Ryanodine receptor abnormalities may be linked to abnormal systolic function and a decrease in systolic force generation [47]. Findings in transgenic mice expressing a SERCa2 transgene driven by a promoter, which does not contain thyroid hormone response elements, lead to a complete rescue of the hypothyroid contractile phenotype as mentioned above [27].

\section{Interaction between $\mathrm{T} 3$ action and heart failure-induced signaling mechanisms}

A crosstalk between signaling cascades related to thyroid hormone mediated increases in SERCa2 expression and factors, which are altered in heart failure, have been noted in the past. For example, when neonatal myocytes are transfected with the SERCa2 promoter and $\beta$ galactyocydase ( $\beta$-bal) reporter, addition of thyroid hormone leads to a two-fold increase in expression of the 3.2 KB SERCa2 promoter driven $\beta$-bal reporter. Incubation of these neonatal myocytes with a combination of $\mathrm{T} 3$ and the cytokines LIF and 1L-6 [48] completely abolished the T3 mediated increase in SERCa2 promoter-reporter activity. These findings indicate that increased levels of cytokines, as they occur with heart failure, can markedly counteract thyroid hormone-mediated increases in the expression of SERCa2.

It can be demonstrated that hypothyroidism, including sub-clinical hypothyroidism, is a risk factor for heart 
failure [38-40]. Both hypothyroidism and heart failure result in delayed diastolic relaxation and abnormal calcium handling. Both hypothyroidism and heart failure lead to decreased expression of SERCa2. In addition, the inhibitory action of phospholamban is enhanced, either due to increased phospholamban expression or due to decreased phospholamban phosphorylation. Heart failure is frequently accompanied by elevated cytokine levels and cytokines oppose the positive regulatory effects of thyroid hormone on SERCa2 expression.

\section{Heart failure and ischemia decrease thyroid hormone signaling members}

Interactions between thyroid hormone action and heart failure are also noted in the non-thyroidal illness syndrome (NTIS). The non-thyroidal illness syndrome results, when severe systemic illness including heart failure or myocardial infarction leads to changes in the function of the hypothalamic pituitary axis. A decrease in $\mathrm{T} 4$ to $\mathrm{T} 3$ conversion occurs, which is followed by decreased secretion of thyroid stimulating hormone (TSH) and diminished thyroid hormone release from the thyroid gland. Hallmark laboratory findings of NTIS are decreases in T3, increases in reverse $\mathrm{T} 3$, which are followed by decreases in $\mathrm{T} 4$ and TSH. With recovery from the severe illness, a rebound happens and TSH levels can exceed the upper normal range for a short while before re-adjustment to a normal condition occurs and normalization of thyroid hormone levels follows. It is interesting to note that cytokines have been invoked to play a significant role in inducing the nonthyroidal illness syndrome. Several recent reports indicate that a very strong correlation exists between the decrease in T3 levels induced by congestive heart failure and the survival [49]. The report demonstrates that the lower the heart failure-induced decrease in $\mathrm{T} 3$ is the more significant of a decrease in survival occurs. The connection between thyroid hormone signaling and heart failure is also documented in studies in which thyroid hormone receptor levels were determined in explanted hearts from patients undergoing cardiac transplantation [50]. In one report, a significant decrease of thyroid hormone receptor alpha 1 expression and an increase in the non-ligand binding thyroid hormone receptor alpha 2 isoform were noted [50]. We pursued these studies in a mouse model using ascending aortic constriction to induce cardiac hypertrophy and heart failure [51]. We then quantitated the mRNA level for thyroid hormone receptor alpha 1 and beta 1 . Both thyroid hormone receptor alpha 1 and beta 1 were significantly decreased in the pressure overloaded failing hearts. Other investigators have reported that ischemic heart disease leads to alterations in thyroid hormone receptor levels [52].
In addition, it has been reported that in ischemic heart disease the deiodinase type 3 , which converts $\mathrm{T} 4$ to the biologically inactive reverse $\mathrm{T} 3$ is markedly elevated [53]. Furthermore, inducing right cardiac ventricular hypertrophy by a model of pulmonary hypertension resulted in significant increases in the type 3 diodonase (D3) [54]. The mechanism leading to D3 induction was explored in more detail and the HIF1 alpha factor was found to directly stimulate the promoter of the $\mathrm{T} 3$ deiodinase gene resulting in increased $\mathrm{T} 3$ expression [55].

It could therefore be postulated that a close interaction between thyroid hormone action and normal cardiac function occurs. Hypothyroidism, including sub-clinical hypothyroidism, presents a risk to develop heart failure. In addition, the non-thyroidal illness syndrome, which is in part, mediated by cytokines leads to decreased thyroid hormone receptor levels in the failing heart and in some specific conditions to increased conversion of $\mathrm{T} 4$ to the biologically inactive reverse $\mathrm{T} 3$. It could therefore be postulated that the non-thyroidal illness syndrome generates a "hypothyroid" heart characterized by decreased T3 levels and decreased thyroid hormone receptor levels. It is therefore an interesting question to examine if increasing thyroid hormone action in the failing heart will result in improved cardiac function.

In order to address the question if increasing T3 action in the failing heart improves cardiac function, we pursued the following studies. Ascending aortic constriction was induced in mice, which resulted in pressure overloadinduced heart failure [51]. As it was mentioned above, thyroid hormone receptor alpha and beta levels are decreased in these hearts. In order to restore thyroid hormone receptor levels toward the normal range, thyroid hormone receptor alpha 1 and beta 1 were cloned into adeno-associated viruses and injected into the left ventricular wall of the heart. In addition, some of these animals received a physiological replacement dose of $3.5 \mathrm{ngT3} / \mathrm{gBW}$ per day. Two weeks after administration of viral vector-based thyroid hormone receptor expression and $\mathrm{T} 3$ administration, the rate of cardiac relaxation was determined. When we determined $\mathrm{dP} / \mathrm{dt}$ min as a parameter of cardiac relaxation, we noted that in pressure overloaded heart with increased expression of thyroid hormone receptor alpha or thyroid hormone receptor beta, a very significant increase in the speed of diastolic relaxation occurred, however complete normalization was not achieved. The addition of a T3 replacement dose did not lead to a further significant increase in contractile improvement. It has also been reported that a tetracycline systembased inducible increased the expression of the deiodinase type 2 , which converts $\mathrm{T} 4$ to $\mathrm{T} 3$, in the heart of animals with pressure overload-induced cardiac hypertrophy led to a significant improvement in systolic and diastolic contractile function [56]. 
These studies in animal models therefore indicate that increasing thyroid hormone levels in failing hearts by AV expression leads to a significant and equal rescue effect by thyroid hormone receptor alpha 1 and beta 1 . In addition, increasing T3 levels in the failing heart by increasing D2 activity also markedly improves contractile function. It appears therefore that the heart failure-induced lowering of thyroid hormone levels or thyroid hormone receptor levels in the failing heart exerts a mal-adaptive effect.

Previous studies in human beings, in which T3 therapy was administered to patients after cardiac surgery revealed a beneficial effect in lowering the incidence of atrial fibrillation [57]. In other studies thyroxin treatment had a beneficial effect on dilated cardiomyopathy [58]. A very recent trial indicates that $\mathrm{T} 3$ replacement in patients with heart failure has beneficial contractile effects [59]. It should also be noted that in other studies intravenous T3 administration to patients undergoing coronary artery bypass graft surgery in randomized double-blind placebo controlled trials did not lead to significant cardiac improvement [60]. Overall, it appears that in failing hearts, a hypothyroid cardiac state may occur due to decreased thyroid hormone and thyroid hormone receptor levels in failing hearts. Animal studies and a limited number of human trials indicate that increasing thyroid hormone action either by increasing $\mathrm{T} 3$ receptor levels or T3 in itself can improve cardiac function without significant detrimental effects. It is currently unclear if long term administration of thyroid hormone to patients in heart failure will be well tolerated and will lead to increased survival. Excessive thyroid hormone administration leading to a hyperthyroid state needs to be avoided because negative electrophysiological consequences such as an increase in heart rate and cardiac arrhythmias could result.

Open Access This article is distributed under the terms of the Creative Commons Attribution Noncommercial License which permits any noncommercial use, distribution, and reproduction in any medium, provided the original author(s) and source are credited.

\section{References}

1. Klein I, Ojamaa K (2001) Thyroid hormone and the cardiovascular system. N Engl J Med 344(7):5011-5019. doi:10.1056/ NEJM200102153440707

2. Kahaly GJ, Dillmann WH (2005) Thyroid hormone action in the heart. Endocr Rev 26(5):704-728. doi:10.1210/er.2003-0033 Epub 2005 Jan 4

3. Fazio S, Palmieri EA, Lombardi G, Biondi B (2004) Effects of thyroid hormone on the cardiovascular system. Recent Prog Horm Res 59:31-50. doi:10.1210/rp.59.1.31

4. Sawin CT (2002) Subclinical hyperthyroidism and atrial fibrillation. Thyroid 12(6):501-503. doi:10.1089/105072502760143881

5. Parmar MS (2005) Thyrotoxic atrial fibrillation. MedGenMed $7(1): 74$
6. Pantos C, Mourouzis I, Markakis K, Tsagoulis N, Panagiotou M, Cokkinos DV (2008) Long-term thyroid hormone administration reshapes left ventricular chamber and improves cardiac function after myocardial infarction in rats. Basic Res Cardiol 103(4):308 318. doi:10.1007/s00395-008-0697-0 Epub 2008 Feb 15

7. Gupta MP (2007) Factors controlling cardiac myosin-isoform shift during hypertrophy and heart failure. J Mol Cell Cardiol 43(4):388403. doi:10.1016/j.yjmcc.2007.07.045 Epub 2007 Jul 21

8. Tomanek RJ, Zimmerman MB, Suvarna PR, Morkin E, Pennock GD, Goldman S (1998) A thyroid hormone analog stimulates angiogenesis in the post-infarcted rat heart. J Mol Cell Cardiol 30(5):923-932. doi:10.1006/jmcc.1998.0671

9. Khalife WI, Tang YD, Kuzman JA, Thomas TA, Anderson BE, Said S, Tille P, Schlenker EH, Gerdes AM (2005) Treatment of subclinical hypothyroidism reverses ischemia and prevents myocyte loss and progressive LV dysfunction in hamsters and dilated cardiomyopathy. Am J Physiol. Heart Circ Physiol 289(6):H2409H2415. doi:10.1152/ajpheart.00483.2005 Epub 2005 Jul 15

10. Gay R, Lee RW, Appleton C, Olajos M, Martin GV, Morkin E, Goldman S (1987) Control of cardiac function and venous return in thyrotoxic calves. Am J Physiol 252(3 Pt 2):H467-H473

11. Danzi S, Klein I (2003) Thyroid hormone and blood pressure regulation. Curr Hypertens Rep 5(6):513-520. doi:10.1007/s11906-0030060-7

12. Duntas LH (2002) Thyroid disease and lipids. Thyroid 12(4): 287-293. doi:10.1089/10507250252949405

13. Palmieri EA, Fazio S, Lombardi G, Biondi B (2004) Subclinical hypothyroidism and cardiovascular risk: a reason to treat? Treat Endocrinol 3(4):233-244. doi:10.2165/00024677-200403040-00005

14. Yen PM, Ando S, Feng X, Liu Y, Maruvada P, Xia X (2006) Thyroid hormone action at the cellular, genomic and target gene levels. Mol Cell Endocrinol 246(1-2):121-127. doi:10.1016/j.mce.2005.11. 030 Epub 2006 Jan 25

15. McKenna NJ, O'Malley BW (2002) Minireview: nuclear receptor coactivators-an update. Endocrinology 143(7):2461-2465. doi: 10.1210/en.143.7.2461

16. Bassett JH, Harvey CB, Williams GR (2003) Mechanisms of thyroid hormone receptor-specific nuclear and extra nuclear actions. Mol Cell Endocrinol 213(1):1-11. doi:10.1016/j.mce.2003.10. 033

17. Plateroti M, Gauthier K, Domon-Dell C, Freund JN, Samarut J, Chassande O (2001) Functional interference between thyroid hormone receptor alpha (TRalpha) and natural truncated TR/Delta/ alpha isoforms in the control of intestine development. Mol Cell Biol 21(14):4761-4772. doi:10.1128/MCB.21.14.4761-4772.2001

18. Wrutniak C, Cassar-Malek I, Marchal S, Rascle A, Heusser S, Keller JM, Fléchon J, Dauça M, Samarut J, Ghysdael J et al (1995) A 43-kDa protein related to c-Erb A alpha 1 is located in the mitochondrial matrix of rat liver. J Biol Chem 270(27): 16347-16354. doi:10.1074/jbc.270.27.16347

19. Davis PJ, Leonard JL, Davis FB (2008) Mechanisms of nongenomic actions of thyroid hormone. Front Neuroendocrinol 29(2): 211-218 Epub 2007 Oct 5

20. Levin ER (2008) Rapid signaling by steroid receptors. Am J Physiol Regul Integr Comp Physiol 295(5):R1425-R1430

21. Rohrer DK, Hartong R, Dillmann WH (1991) Influence of thyroid hormone and retinoic acid on slow sarcoplasmic reticulum $\mathrm{Ca} 2+\mathrm{ATPase}$ and myosin heavy chain alpha gene expression in cardiac myocytes. Delineation of cis-active DNA elements that confer responsiveness to thyroid hormone but not to retinoic acid. J Biol Chem 266(13):8638-8646

22. Gloss B, Giannocco G, Swanson EA, Moriscot AS, Chiellini G, Scanlan T, Baxter JD, Dillmann WH (2005) Different configurations of specific thyroid hormone response elements mediate opposite effects of thyroid hormone and GC-1 on gene 
expression. Endocrinology 146(11):4926-4933. doi:10.1210/en. 2005-0631 (Epub 2005 Aug 4)

23. van Rooij E, Sutherland LB, Qi X, Richardson JA, Hill J, Olson EN (2007) Control of stress-dependent cardiac growth and gene expression by a microRNA. Science 316(5824):575-579. doi: 10.1126/science.1139089 Epub 2007 Mar 22

24. Fraichard A, Chassande O, Plateroti M, Roux JP, Trouillas J, Dehay C, Legrand C, Gauthier K, Kedinger M, Malaval L (1997) The T3R alpha gene encoding a thyroid hormone receptor is essential for post-natal development and thyroid hormone production. EMBO J 16(14):4412-4420. doi:10.1093/emboj/16.14. 4412

25. Gauthier K, Chassande O, Plateroti M, Roux JP, Legrand C, Pain B, Rousset B, Weiss R, Trouillas J, Samarut J (1999) Different functions for the thyroid hormone receptors TRalpha and TRbeta in the control of thyroid hormone production and post-natal development. EMBO J 18(3):623-631. doi:10.1093/emboj/18.3. 623

26. Gloss B, Trost S, Bluhm W, Swanson E, Clark R, Winkfein R, Janzen K, Giles W, Chassande O, Samarut J, Dillmann W (2001) Cardiac ion channel expression and contractile function in mice with deletion of thyroid receptor alpha or beta. Endocrinology 142(2):544-550. doi:10.1210/en.142.2.544

27. Blumh WF, Meyer M, Sayen MR, Swanson EA, Dillmann WH (1999) Overexpression of sarcoplasmic reticulum Ca(2+)-ATPase improves cardiac contractile function in hypothyroid mice. Cardiovasc Res 43(2):382-388. doi:10.1016/S0008-6363(99)00 109-1

28. Johansson C, Göthe S, Forrest D, Vennström B, Thorén P (1999) Cardiovascular phenotype and temperature control in mice lacking thyroid hormone receptor-beta or both alpha1 and beta. Am J Physiol 276(6 Pt 2):H2006-H2012

29. Wakatsuki T, Schlessinger J, Elson EL (2004) The biochemical response of the heart to hypertension and exercise. Trends Biochem Sci 29(11):609-617. doi:10.1016/j.tibs.2004.09.002

30. Dorn GWII (2007) The fuzzy logic of physiological cardiac hypertrophy. Hypertension 49(5):962-970. doi:10.1161/HYPER TENSIONAHA.106.079426 Epub 2007 Mar 26

31. Houser SR, Molkentin JD (2008) Does contractile Ca2+control calcineurin-NFAT signaling and pathological hypertrophy in cardiac myocytes? Sci Signal 1(25):pe31. doi:10.1126/scisignal. 125pe31

32. Shiojima I, Sato K, Izumiya Y, Schiekofer S, Ito M, Liao R, Colucci WS, Walsh K (2005) Disruption of coordinated cardiac hypertrophy and angiogenesis contributes to the transition to heart failure. J Clin Investig 115(8):2108-2118. doi:10.1172/JCI 24682

33. Ojaimi C, Qanud K, Hintze TH, Recchia FA (2007) Altered expression of a limited number of genes contributes to cardiac decompensation during chronic ventricular tachypacing in dogs. Physiol Genomics 29(1):76-83. doi:10.1152/physiolgenomics. 00159.2006 Epub 2006 Dec 12

34. Siu CW, Yeung CY, Lau CP, Kung AW, Tse HF (2007) Incidence, clinical characteristics and outcome of congestive heart failure as the initial presentation in patients with primary hyperthyroidism. Heart (British Cardiac Society) 3(4):483-487. doi:10.1136/ hrt.2006.100628 Epub 2006 Sep 27

35. Boccalandro C, Boccalandro F, Orlander P, Wei CF (2003) Severe reversible dilated cardiomyopathy and hyperthyroidism: case report and review of the literature. Endocr Prac 9(2):140-146

36. Siu CW, Zhang XH, Yung C, Kung AW, Lau CP, Tse HF (2007) Hemodynamic changes in hyperthyroidism-related pulmonary hypertension: a prospective echocardiographic study. J Clin Endocrinol Metab 92(5):1736-1742. doi:10.1210/jc.2006-1877 Epub 2007 Feb 27
37. Ismail HM (2007) Reversible pulmonary hypertension and isolated right-sided heart failure associated with hyperthyroidism. J Gen Intern Med 22(1):148-150. doi:10.1007/s11606-006-0032-0

38. Shuvy M, Shifman OE, Nusair S, Pappo O, Lotan C (2008) Hypothyroidism-induced myocardial damage and heart failure: an overlooked entity. Cardiovasc Pathol Feb 21. Epub ahead of print

39. Schmidt-Ott UM, Ascheim DD (2006) Thyroid hormone and heart failure. Curr Heart Fail Rep 3(3):114-119. doi:10.1007/s11897006-0010-1

40. Rodondi N, Bauer DC, Cappola AR, Cornuz J, Robbins J, Fried LP, Ladenson PW, Vittinghoff E, Gottdiener JS, Newman AB (2008) Subclinical thyroid dysfunction, cardiac function, and the risk of heart failure. The Cardiovascular Health study. J Am Coll Cardiol 52(14):1152-1159. doi:10.1016/j.jacc.2008.07.009

41. Ladenson PW, Sherman SI, Baughman KL, Ray PE, and Feldman AM (1992) Reversible alterations in myocardial gene expression in a young man with dilated cardiomyopathy and hypothyroidism. Proc Natl Acad Sci USA 89(12):5251-5255. doi:10.1073/pnas. 89.12.5251

42. Reed TD, Babu GJ, Ji Y, Zilberman A, Ver Heyen M, Wuytack F, Periasamy M(2000) The expression of calcium SR transport ATPase and the $\mathrm{Na}(+) / \mathrm{Ca}(2+)$ Exchanger are antithetically regulated during mouse cardiac development and in Hypo/hyperthyroidism. J Mol Cell Cardiol 32(3):453-464. doi:10.1006/jmcc.1999.1095

43. Cernohorsky J, Kolár F, Pelouch V, Korecky B, Vetter R (1998) Thyroid control of sarcolemmal $\mathrm{Na}+/ \mathrm{Ca} 2+$ exchanger and SR $\mathrm{Ca} 2+-\mathrm{ATPase}$ in developing rat heart. Am J Physiol 275(1 Pt 2): $\mathrm{H} 264-\mathrm{H} 273$

44. Waggoner JR, Kranias EG (2005) Role of phospholamban in the pathogenesis of heart failure. Heart Fail Clin 1(2):207-218. doi: 10.1016/j.hfc.2005.03.008

45. Ojamaa K, Kenessey A, Klein I (2000) Thyroid hormone regulation of phospholamban phosphorylation in the rat heart. Endocrinology 141(6):2139-2144. doi:10.1210/en.141.6.2139

46. Arai M, Otsu K, MacLennan DH, Alpert NR, Periasamy M (1991) Effect of thyroid hormone on the expression of mRNA encoding sarcoplasmic reticulum proteins. Circ Res 69(2): 266-273

47. Wehrens XH, Lehnart SE, Marks AR (2005) Intracellular calcium release and cardiac disease. Annu Rev Physiol 67:69-98. doi: 10.1146/annurev.physiol.67.040403.114521

48. Gloss B, Villegas S, Villarreal FJ, Moriscot A, Dillmann WH (2000) Thyroid hormone-induced stimulation of the sarcoplasmic reticulum $\mathrm{Ca}(2+)$ ATPas gene is inhibited by LIF and IL-6. Am J Physiol. Endocrinol Metab 278(4):E738-E743

49. Iervase G, Pingitore A, Landi P, Raciti M, Ripoli A, Scarlattini M, L'Abbate A, Donato L (2003) Low-T3 syndrome: a strong prognostic predictor of death in patients with heart disease. Circulation 107(5):708-713. doi:10.1161/01.CIR.0000048124.64 204.3F

50. Kinugawa K, Minobe WA, Wood WM, Ridgway EC, Baxter JD, Ribeiro RC, Tawadrous MF, Lowes BA, Long CS, Bristow MR (2001) Signaling pathways responsible for fetal gene induction in the failing human heart: evidence for altered thyroid hormone receptor gene expression. Circulation 103(8):1089-1094

51. Belke DD, Gloss B, Swanson EA, Dillmann WH (2007) Adenoassociated virus-mediated expression of thyroid hormone receptor isoforms-alpha1 and -beta1 improves contractile function in pressure overload-induced cardiac hypertrophy. Endocrinology 148(6):2870-2877. doi:10.1210/en.2007-0009 Epub 2007 Feb 22

52. Pantos C, Dritsas A, Mourouzis I, Dimopoulos A, Karatasakis G, Athanassopoulos G, Mavrogeni S, Manginas A, Cokkinos DV (2007) Thyroid hormone is a critical determinant of myocardial performance in patients with heart failure: potential therapeutic 
implications. Eur J Endocrinol 157(4):515-520. doi:10.1530/ EJE-07-0318

53. Olivares EL, Marassi MP, Fortunato RS, da Silva AC, Costa-eSousa RH, Araújo IG, Mattos EC, Masuda MO, Mulcahey MA, Huang SA, Bianco AC, Carvalho DP (2007) Thyroid function disturbance and type 3 iodothyronine deiodinase induction after myocardial infarction in rats a time course study. Endocrinology 148(10):4786-4792. doi:10.1210/en.2007-0043 Epub 2007 Jul 12

54. Wassen FW, Schiel AE, Kuiper GG, Kaptein E, Bakker O, Visser TJ, Simonides WS (2002) Induction of thyroid hormonedegrading deiodinase in cardiac hypertrophy and failure. Endocrinology 143(7):2812-2815. doi:10.1210/en.143.7.2812

55. Simonides WS, Mulcahey MA, Redout EM, Muller A, Zuidwijk MJ, Visser TJ, Wassen FW, Crescenzi A, da-Silva WS, Harney J, Engel FB, Obregon MJ, Larsen PR, Bianco AC, Huang SA (2008) Hypoxia-inducible factor induces local thyroid hormone inactivation during hypoxic-ischemic disease in rats. J Clin Invest 118(3):975-983

56. Trivieri MG, Oudit GY, Sah R, Kerfant BG, Sun H, Gramolini AO, Pan Y, Wickenden AD, Croteau W, Morreale de Escobar G, Pekhletski R, St Germain D, Maclennan DH, Backx PH (2006) Cardiacspecific elevations in thyroid hormone enhance contractility and prevent pressure overload-induced cardiac dysfunction. Proc Natl Acad Sci USA 103(15):6043-6048 Epub 2006 Apr 4. doi:10.1073/ pnas.0601072103

57. Klemperer JD, Klein I, Gomez M, Helm RE, Ojamaa K, Thomas SJ, Isom OW, Krieger K (1995) Thyroid hormone treatment after coronary-artery bypass surgery. N Engl J Med 333(23):15221527. doi:10.1056/NEJM199512073332302

58. Moruzzi P, Doria E, Agostoni PG (1996) Medium-term effectiveness of L-thyroxine treatment in idiopathic dilated cardiomyopathy. Am J Med 101(5):461-467. doi:10.1016/S0002-9343(96)00281-1

59. Pingitore A, Galli E, Barison A, Iervasi A, Scarlattini M, Nucci D, L'abbate A, Mariotti R, Iervasi G (2008) Acute effects of triiodothyronine (T3) replacement therapy in patients with chronic heart failure and low-T3 syndrome: a randomized, placebo-controlled study. J Clin Endocrinol Metab 93(4):1351-1358. doi:10.1210/ jc.2007-2210 Epub 2008 Jan 2

60. Bennett-Guerrero E, Jimenez JL, White WD, D'Amico EB, Baldwin BI, Schwinn DA (1996) Cardiovascular effects of intravenous triiodothyronine in patients undergoing coronary artery bypass graft surgery. A randomized, double-blind, placebocontrolled trial. Duke T3 study group. J Am Med Assoc 275(9): 687-692. doi:10.1001/jama.275.9.687 